\title{
Research Based on Patent Analysis about the Present Status and Development Trends of Unmanned Aerial Vehicle in China
}

\author{
Qi Liu, Zhangzhi Ge, Wei Song \\ School of Public Affairs, University of Science and Technology of China, Hefei, China \\ Email: Eureka@mail.ustc.edu.cn
}

Received 21 June 2016; accepted 22 July 2016; published 25 July 2016

Copyright (C) 2016 by authors and Scientific Research Publishing Inc.

This work is licensed under the Creative Commons Attribution International License (CC BY). http://creativecommons.org/licenses/by/4.0/

(c) (i) Open Access

\begin{abstract}
For knowing the present status and development trends of unmanned aerial vehicle (UAV) in China, the paper uses patent analysis method to carry out quantitative and qualitative research based on technology life cycle theory. The research concludes that China's UAV technology has been in the period of growth stage with large development potential and an increasingly number of technology fields are springing up. But some problems, such as low percentage of invention patent, single type of innovation subject, weakness of innovation ability and imbalance in development of different region, still exist. In order to promote the equalization, standardization and internationalization of UAV industry, the paper puts forward some recommendations.
\end{abstract}

\section{Keywords}

Patent Analysis, UAV, Development Status, Development Trends

\section{Introduction}

The development of new technology and industry is a new growth point of the world economy, which has become the strategic choice in future among many countries in the world. In order to foster the development of new industry and seize the commanding point of economy and technology, the State Council promulgated the "China's 12th Five-Year Plan for Development of Strategic Emerging Industry", which proposed the development direction and main tasks were energy saving industry, new generation information industry and high-end manufacture industry, etc. Besides, "Made in China 2025" put forward that we should support and accelerate the development of aeronautics and astronautics equipment. In 2015, the Rand Corp report "Emerging Trends in 
China's Development of Unmanned Systems” concluded that China had made a significant progress in the field of UAV in the past few years, and had become a pivotal role in the global marketplace [1]. The global market for UAV industry is expected to reach USD 70.98 billion in the next decade according to a study [2]. As an important symbol of measuring the level of a country's high-end manufacture industry, exploration and practice of UAV industry achieve substantial progress, which not only lay a solid foundation itself but also provide significant opportunities to transform and upgrade traditional industries. UAV has been a hot point in the area of automatic control in recent years, thanks to its potential applications in multiple areas, such as military, rescue, aerial photography, plant protection and remote sensing. To better understand the technology development status and outline the blueprint of the whole industry, we use patent analysis method to analyze the patent about UAV granted in China. We hope that the research will be helpful to promote the innovation and development of UAV industry and enrich the theoretical research in relevant fields.

\section{Method and Data}

As an useful method, patent analysis is a crucial technique for predicting technology trends, reflecting the innovation ability of a country or region, analyzing potential markets, determining the direction of technological development, and providing appropriate decision references for governments and enterprises. With the continuous progress of knowledge economy, the innovation ability should not be judged by the number of patent applications and patent grants, but by the number and quality of valid patents [3]. Only those valid patents can bring benefits to innovation subjects, and be considered as national instruments and means in international competition [4]. We summarize researches about patent analysis, and find the existing achievements as the basis for the study. The data from 2003 to 2014 was collected from the online database in SIPO (the State Intellectual Property Office of the P.R.C). A proper retrieval strategy is the foundation of patent analysis. To define the keywords about "Unmanned Aerial Vehicle", we figure out the synonymous words in Chinese and English. By combing the keywords together, an overall patent retrieval is made as follows: UAV or Drone or Unmanned aerial vehicle or Unmanned aircraft or pilotless aircraft or unmanned planes or Unmanned helicopter or autonomous helicopter or pilotless helicopter. After data filtering and manual de-noising, 1677 valid patent records were retrieved as analytical samples by December 1, 2015. Loglet Lab2.0, Ucinet6.0 and VOSviewer are used in the study.

\section{Present Status of UAV Technology in China}

\subsection{Patent Structure Analysis}

As is shown in Figure 1, the overall patent records is 1677 consisting of 282 invention patent records which account for $16.82 \%, 1226$ utility models patent records which account for $73.11 \%$ and 169 design patent records which account for $10.08 \%$. It's clear that the patent structure is mainly composed of utility models patent, while the proportion of invention patent and design patent is very low. Thus, the phenomenon implies that the technology content of UAV industry in China is not high, the level of innovation is still relatively weak. There is great room to upgrade, we need to increase investment more in innovation resources and talents cultivation to gain competition advantages in global markets.

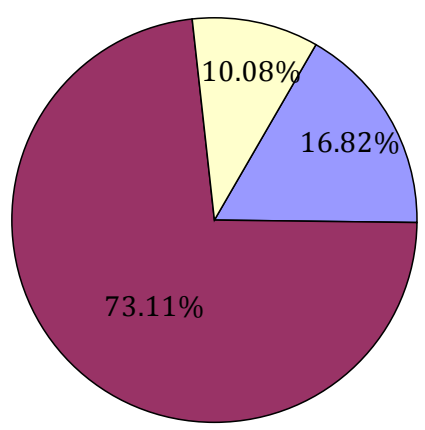

$\square$ Inventions $\square$ Utinity models $\square$ Designs

Figure 1. The patent structure of UAV in China. 


\subsection{Annual Distribution Analysis}

Figure 2 shows that the number of valid patents of the UAV in China grows exponentially, and the rising trend is obvious over time. It reveals the annual tendency of changes on 3 kinds of patent related to UAV. It's obvious that the development of UAV technology could be divided into 3 stages. Firstly, the development went through embryonic stage from 2003 to 2006, and the annual number of patents grew slowly, less than 10 per year. The second stage showed the feature that the growth rate was very fast reaching to $90.50 \%$, but the annual number of patents was still small, no more than 100 per year during the period between 2007 and 2010. Since 2011, the number of patents related to UAV experienced a sharp rise and reached the peak point in 2014. As the unceasing development of UAV technology and market demands, the annual number of patents increased from 166 to 742 in just 4 years. We believe that the number of patents processed could be because some of the patents are easier to read, new systems in place, perhaps more efficient work habits and assume that along with the global attention to UAV industry, there will be a large number of patent outputs in the next few years.

\subsection{Regional Distribution Analysis}

In terms of region, the result shows that the number of patents in the Eastern, Central and Western part of China is obvious dissimilarity, which accounts for $67.23 \%$; $17.68 \%$ and $14.91 \%$. The feature of patent regional distribution appears on a diminishing scale from east to the west. More information can be found in Figure 3. The top three provinces (municipalities) are, by rank, Beijing, Guangdong and Jiangsu in the number of patents. These provinces have natural advantages of other provinces in strong economic foundations, various scientific research institutions as well as superb innovation ability and environment. Hubei and Sichuan province are the development leader in the Central and Western part of China respectively. EWATT Technology Co., Ltd is the first UAV enterprise in central China. China's first commercial UAV industry alliance was established in 2014 in Sichuan so as to help the development of UAV research by integrating advantage resources and constructing industrial chain. At present, the number of overseas-originated patents granted by China and their patent layout scale are small. The number of granted patents in China of France, Korea, USA, Germany, Belgium and Austria granted is 5, 3, 2, 2, 1 and 1 in details.

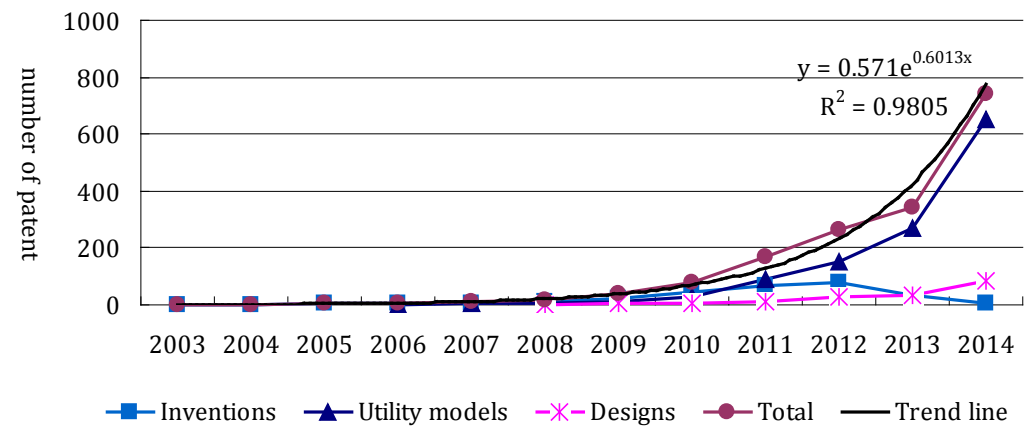

Figure 2. The number of UAV patent per year.

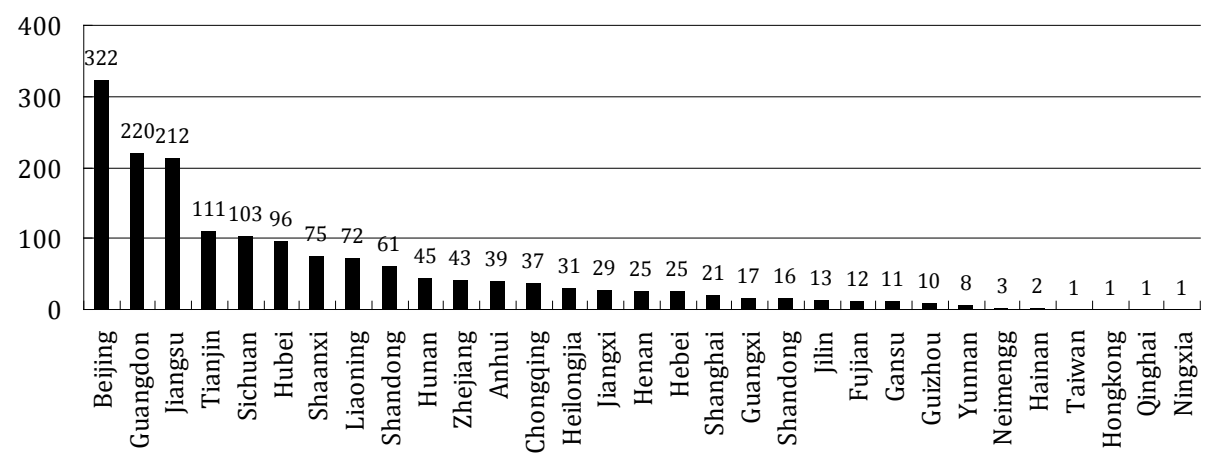

Figure 3. The number of UAV patent in different province. 


\subsection{Technical Fields Analysis}

Due to the limited number of patents, we classify and count the number of technical fields according to IPC patent class codes. In total, the database held 1677 patent records, which corresponded to 502 different technical fields. The top 10 technical fields are summarized in Table 1 . Because of the limited space, parts of assignees of each technical field are listed in Table 1. Prominent and popular research areas are UAV designs (12-07), power system of UAV (B64C27/08), navigation system of UAV (G05D1/10), aerial photography system of UAV (B64D47/08) and plant protection system of UAV (B64D1/18), etc. UAV design (12-07) is the only one technical field which holds more than 100 patents.

By analyzing patent output of assignees, we can assess their strength of technology competitiveness [5]. The result shows the following characteristics: 1) the number and difference of patents of each assignees are small; 2) enterprises have strong advantages in competition among every technical fields of UAV technology; 3) Beihang University has more advantages on navigation system of UAV; 4) technical fields of State Grid Corporation of China is varied, while other assignees is relatively simple. Overall, the technical fields of UAV research continues to expand from UAV designs to new areas such as power system, navigation system and plant protection system and so on, which provide a broader space and accelerate the application of UAV technology in new domains. However, in view of main assignees, some problems, such as low number of high-quality patents, low level of technology, narrowness of technical fields and weakness of R\&D capabilities, still exist.

\subsection{Assignees Analysis}

We divide the assignees into six types, including individuals, universities, research institutes, enterprises, foreign enterprises and mixed subjects. Mixed subjects are defined as those patents with two or more assignees. Table 2 shows the top 10 assignees who contributed greatly in research of innovation in areas related to UAV technology. Beijing University of Aeronautics and Astronautics is the only non-enterprise unit appearing in the top 10 assignees list. We can assume that enterprises is the most important assignees, accounting for 55.64\%, followed by universities, research institutions, mixed subjects, individuals, foreign enterprises, accounting for 14.13\%, 11.93\%, 10.02\%, 7.81\%, 0.48\%, respectively. Enterprises have high enthusiasm in the innovation of UAV technology, while the involvement of universities and research institutions is low to some extent.

Due to the limited space, only top 4 assignees are selected to demonstrate the following analysis. We observe that State Grid Corporation of China, with 58 patents, filed the maximum number of patents, whose research area mainly focus on UAV power patrol system, including H02G1/02, B64C27/08, B64D47/08 and G05D1/10. However, all the patents come from joint applications with other assignees, lacking of independent innovation. Ewatt Technology Co., Ltd, with 51 patents, comes in second place, whose research area mainly focus on the structure and power system of UAV, including 12-07, B64D33/02 and B64D27/02. It's target market is industrialgrade market and comprehensive strength ranks the forefront of UAV domain in China. Beihang University

Table 1. Top 10 technical fields and their main assignees.

\begin{tabular}{lcl}
\hline Technical Fields & Number & Main Assignees \\
\hline 12-07 & 119 & All-China-times Aerospace Technology and Development Co., Ltd. (9) \\
B64C27/08 & 72 & Aeritech UAV Technology Co., Ltd. (4), AIbird UAV Co., Ltd. (4) \\
G05D1/10 & 64 & Beihang University (7), State Grid Corporation of China (4) \\
B64D47/08 & 53 & State Grid Corporation of China (5), AEE technology Co., Ltd. (5), DJI Technology Co., Ltd. (3) \\
B64D1/18 & 45 & Kingtec Aviation Industry Co., Ltd. (8), Tongchun New Energy Technology Co., Ltd. (5) \\
B64C1/00 & 42 & Kingtec Aviation Industry Co., Ltd. (8) \\
B64D47/00 & 37 & Aeritech UAV Technology Co., Ltd. (2), Union of Science and Technology Co., Ltd. (2) \\
B64C27/02 & 32 & Good Fly Robostar Technology Co., Ltd. (4), Gan Tiantian (3) \\
B64F1/06 & 30 & AIbird UAV Co., Ltd. (4), Special Vehicle Science and Technology Co., Ltd. (2) \\
H02G1/02 & 27 & State Grid Corporation of China (7) \\
\hline
\end{tabular}


Table 2. Top 10 assignees and their main technical fields.

\begin{tabular}{lll}
\hline Assignees & Number & Main Technical Fields \\
\hline State Grid Corporation of China & 58 & H02G1/02 (6), B64C27/08 (5), B64D47/08 (5) \\
Ewatt Technology Co., Ltd. & 51 & 12-07 (5), B64D33/02 (4), B64D27/02 (4) \\
Beihang University & 47 & G05D1/10 (7), G01C21/24(5) \\
All-China-times Aerospace Technology and Development Co., Ltd. & 43 & 12-07 (9), 10-05 (6) \\
Aeritech UAV Technology Co., Ltd. & 34 & B64C27/08 (5), 12-07 (4), B64C25/10 (3) \\
Kingtec Aviation Industry Co., Ltd. & 32 & B64C1/00 (9), B64D1/18 (8), B64C1/14 (7) \\
DJI Technology Co., Ltd. & 29 & B64D47/08 (3), B64C27/08 (2), H05K7/20 (2) \\
Good Flying Robostar Technology Co., Ltd. & 28 & B64C27/08 (8) B64C27/02 (4) \\
China Academy of Aerospace Aerodynamics & 28 & B64C1/00 (3), B64F1/04 (2) \\
AEE technology Co., Ltd. & 23 & B64D47/08 (5) B64C27/32 (3), 12-07 (3) \\
\hline
\end{tabular}

ranks third after State Grid and Ewatt in the number of patents, whose main area is flight control system, including G05D1/10 and G01C21/24. It is the first professional institution which undertakes lots of major and key scientific research projects, specialized in aviation technology. All-China-times Aerospace Technology and Development Co., Ltd ranks fourth, but the level of technology is low in consideration of the fact that technology fields focus on design patents. Finally, it's worth putting out, the enterprise has carried on the patent pledge attempt, which is comparatively rare and offers valuable experience for diverse use of intellectual property of UAV in China.

\section{Development Trend of UAV Technology in China}

\subsection{Technical Life Cycle Analysis}

The trends of technology evolution can be predictable to some degree [6]. TRIZ is a powerful tool to provide systematic and innovative ideas for technology analysis [7]. The TRIZ evolution trends, is a TRIZ tool that reveals the patterns of evolution of business and technology systems, and is useful to evaluate the status of the system today and how it will evolve in the future [8]. Growth curves are widely used in technology forecasting and logistic model is a widely used S-curve foresting model [9].

Thus, the S-curve model adopted by this study is logistic curve model, and it has the equation below

$$
P(t)=\frac{k}{1+\mathrm{e}^{-\alpha(t-\beta)}}
$$

where $P(t)$ and $t$ represent the dependent variable and the time variable for the S-curve respectively, the growth rate parameter $\alpha$ specifies the "width" or "steepness" of the S-curve, $\beta$ specifies the time when the curve reaches $K / 2$, or the midpoint of the growth trajectory, often re-labeled $t_{m}$, and $K$ is a constant meaning the limit value of $P(t)$ when $t$ approaches infinity.

By Loglet Lab2.0, one can forecast how many patents will be generated in the future, and once the possible number of patents is determined, the stage of technology life cycle is estimated and time when the saturation of the technology will occur is computed [10]. Because the value of parameters is hard to determine, the results shown in Table 3 are provided by automatic computation of the curve fitting system. It turns out that the growth time is about 7.58 years and the inflection time is about year 2018. Combining results with current situation and technical life theory, we predict that: 1) in phase one, prior to 2014, is the emerging stage of UAV technology at least in civilian market. In this period, the number of patents related to UAV technology was relatively small; 2) in phase two, UAV technology will get a booming increase until about year 2022 in the stage of growth; 3) UAV technology will step into saturation stage with low growth rates, which can also be perceived as dormant phase of next generation of UAV technology, after about year 2022. Following the analysis mentioned above, this could be interpreted that China's UAV technology has been in the period of growth stage with large development potential and plenty of development time. 
Table 3. Results of logistic curve model of UAV technology.

\begin{tabular}{cc}
\hline Parameters & Value \\
\hline Saturation $(\mathrm{K})$ & 21719.28 \\
Midpoint $\left(\mathrm{t}_{\mathrm{m}}\right)$ & 2018.28 \\
Growth Time $(\mathrm{dT})$ & 7.58 \\
\hline
\end{tabular}

\subsection{Development Trends of Technical Fields}

The changing trends of number of top 10 technical fields are shown in Table 4. By comparing changes in the number of technical fields in aim to grasp the development trend of UAV technology, one may find that almost all technical fields in Table 4 show a tendency to increase. The top 10 technical fields can be roughly divided into three groups according to quantity changes. The first group consist of H02G1/02 (for overhead lines or cables), with low quantities and fluctuations; the second group has the features of obvious changes in quantities and fast growth rates, such as 12-07 (aircraft and air vehicles), B64C27/08 (with two or more rotors) and B64D47/08 (arrangements of cameras), etc; and G05D1/10 (control of position or direction) form the third group, with high fluctuations in quantities and turbid trends.

Based on the analysis above, we conclude that: 1) eight technical fields with rapid growth trend will maintain upward momentums and are the key fields in future; 2) with several standards and policies issued about UAV inspection system, including "Configuration guide of UAV inspection system for overhead transmission line”, the technical field H02G1/02 (for overhead lines or cables) will get a booming opportunity for developing; 3) due to the fundament role played by navigation system of whole UAV industry, the technical field G05D1/10 will get considerable national-level funding and support.

Identifying core technologies is essential for formulating national technology strategies and policies for pursuing technological competitive advantage. Centrality is a key index in social networks, which is one way to quantity an individual's structural importance in a group [11]. In social networks, nodes are social entities, which can be individuals or units, and ties are social relationship between two or more nodes at a given time; these can be interactions or associations. Hereafter, technical fields and their connections are defined as nodes and ties in this study. Relevant research has indicated that core technologies have the character of high level of point centrality, while emerging technologies have the character of high betweenness centrality [12].

Top 300 co-occurrence similarity matrix of IPC patent class codes are constructed, through which density map, point centrality and betweenness centrality of UAV technical fields are obtainable by VOSviewer and Ucinet6.0 respectively. As is shown in Table 5 and Figure 4, top 10 technical fields mainly focus on B64C (aeroplanes; helicopters), B64D (equipments for fitting in or to aircraft; flying suits; parachutes; arrangements or mounting of power plants or propulsion transmissions), H04N (pictorial communication), and G05D (systems for controlling or regulating non-electric variables). These technologies with high level of point centrality and betweenness centrality play important roles in patent network of UAV, which are not only the foundation of developing and strengthening of UAV technology, but also bridges to foster collaborative innovation of different technology subjects, and also universal technologies with independent and potential development space. So, when it comes to the layout of technologies related to UAV, these technical fields above cannot be emphasized too much. Only if innovation subjects focus on the development of these technical fields can we promote the overall progress of the entire industry ultimately.

\section{Conclusions and Recommendations}

\subsection{Conclusions}

1) With the rapid increase of the number of patents, UAV technology in China has entered the stage of rapid development. The result can be concluded according to the prediction of S-curve, combining with the current development status. The increase in the number of patents related to UAV is expected to soar over the next few years, reaching the golden time of development. With regard to quality, patent structure is mainly composed of patents for utility models, while the number and proportion of patents for inventions are low. Overall, technical content of UAV technology in China today is not high. 
Table 4. Changing trends of number of top 10 technical fields.

\begin{tabular}{|c|c|c|c|c|c|c|c|c|c|c|c|c|}
\hline Technical fields & 2003 & 2004 & 2005 & 2006 & 2007 & 2008 & 2009 & 2010 & 2011 & 2012 & 2013 & 2014 \\
\hline $12-07$ & & & & & & 1 & 1 & 6 & 8 & 20 & 24 & 59 \\
\hline B64C27/08 & & & & & & 1 & 0 & 1 & 2 & 5 & 8 & 55 \\
\hline G05D1/10 & & & & & & & & & 9 & 26 & 12 & 17 \\
\hline B64D47/08 & & & & & & & & 2 & 2 & 6 & 7 & 36 \\
\hline B64D1/18 & & & & & & & 1 & 0 & 1 & 5 & 13 & 25 \\
\hline B64C1/00 & & & & 1 & 0 & 1 & 0 & 0 & 6 & 6 & 10 & 18 \\
\hline B64D47/00 & 1 & 0 & 0 & 0 & 0 & 0 & 1 & 3 & 2 & 5 & 5 & 20 \\
\hline B64C27/02 & & & & & & & & 2 & 1 & 3 & 5 & 21 \\
\hline B64F1/06 & & & & 1 & 0 & 0 & 0 & 0 & 4 & 4 & 8 & 13 \\
\hline H02G1/02 & & & & & & & 4 & 3 & 5 & 4 & 5 & 6 \\
\hline
\end{tabular}

Table 5. Results of centrality analysis of UAV technology.

\begin{tabular}{cccc}
\hline \multicolumn{2}{c}{ Point centrality } & \multicolumn{2}{c}{ Betweenness Centrality } \\
\hline Technical Fields & Value & Technical Fields & Value \\
\hline B64D47/08 & 6.760 & B64D47/08 & 11.364 \\
B64C27/08 & 6.294 & B64C27/08 & 10.813 \\
B64C1/00 & 4.740 & B64C39/02 & 9.135 \\
B64D47/00 & 4.584 & B64D27/24 & 8.116 \\
B64D1/18 & 4.507 & B64D47/00 & 6.856 \\
B64C39/02 & 4.429 & B64C27/02 & 6.394 \\
B64C27/02 & 3.885 & B64C1/00 & 6.296 \\
H04N7/18 & 3.341 & B64C39/00 & 5.446 \\
B64D27/24 & 3.263 & H04N7/18 & 5.376 \\
B64C27/32 & 2.720 & G05D1/10 & 5.020 \\
\hline
\end{tabular}

2) The technology fields of UAV in China are gradually enriched, but the patent layout is not reasonable. The number of technology fields expands from 2 to more than 500, which is a great significant progress. Some parts of the UAV technology, such as power system and aircraft and navigation technology, show strong technology potentials and advantages. Patent layout defects are reflected in following, such as the imbalances of technology fields, fewer number of PCT applications, and insufficient of expanding and protection of global markets.

3) The main innovation subject of UAV technology in China is enterprise, while universities and research institutions are only complements. Patents of UAV technology mainly lies in the hands of the enterprise, taking a preferred concentration on practicality. Due roles have not been played well by other innovation subjects, such as universities and research institutions, which lead to a problem that the convergences of basic research and industrialization development are not close enough.

4) The integrative ability of R\&D is relatively weak, and the emphasis about technical fields of different innovation subjects is different. Most of the innovation subjects do not have comprehensive UAV research and development capabilities, with limited technical fields, which is not conducive to the overall upgrading of China's UAV technology. In order to play an essential role in the market, innovation subjects have to excavate own superiorities as well as to expand technical fields reasonably. Only those enterprises, with more and broader R\&D foci and technical fields, have diversified products and development potential. 


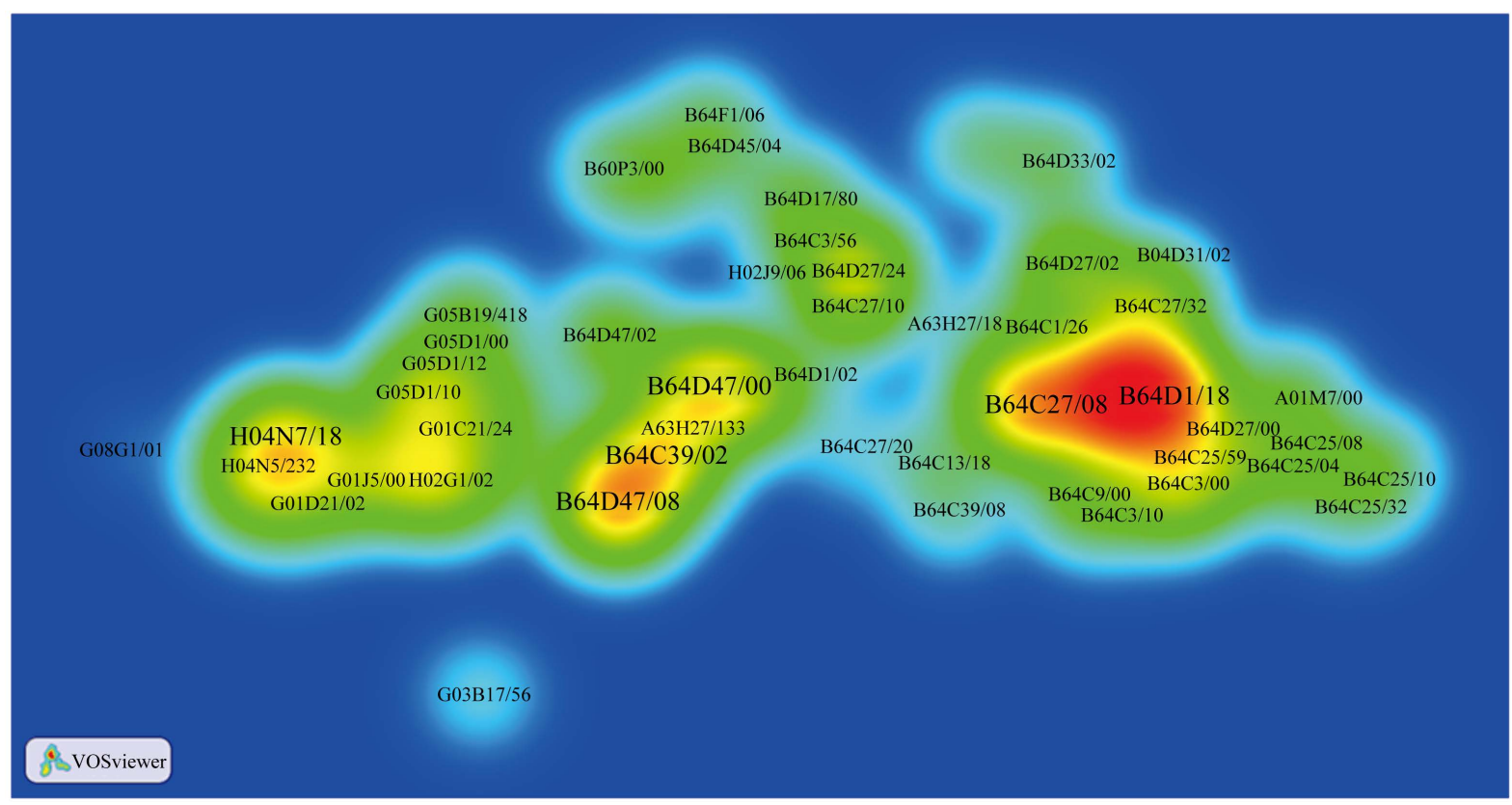

Figure 4. Density map of UAV technology. Note: The color of a point in a density map depends on the number of items in the neighborhood of the point and on the importance of neighboring items [13]. In this red-green-blue color scheme, red corresponds with the highest item density and importance, while blue corresponds with the lowest item density and importance. This is useful to get most important technical fields in patent analysis.

5) Unbalanced regional development of UAV technology, with significant difference in Eastern, Central and Western China. Regions that have high level of technology related to UAV all belong to those with strong economy and technological strength. In general, Beijing, Guangdong and Jiangsu are in the lead position in area of UAV technology, Sichuan and Hubei are important regions in the development of UAV technology in Central and Western China respectively. By patent search, we found that due to some special reasons, the number of UAV patent applications in Shanghai is very small, so the number of valid patents is inadequate, although it's a developed region in China.

\subsection{Recommendations}

Based on the conclusions above, the following countermeasures are put forward.

1) Improving the system of regulations and promoting the construction of industry standards system

So far there is not such country which open low altitude airspace completely, including the United States. Many difficulties, such as policy constrains and legal vacuum, still exist in restricting the widespread adoption of UAV in China. Such restrictive policies could put the country and its companies at a significant disadvantage in the global marketplace. As we all know, sound laws and regulations are the essential condition for sustainable development of UAV industry. Firstly, we should accelerate the reform of the airspace management system, to promote the opening of low altitude airspace. Much effort should be made to solve the existing problems such as closed low altitude airspace, complex management process and too much agency levels, etc. [14]. Secondly, government departments should strengthen guidance and coordinate different interest groups to establish the alliance of UAV industry and intellectual property to perfect UAV industry standards about systems of accession, certification, supervision and service. Finally, intellectual property pledge financing, product export, insurance and other policies should be improved. Besides, in order to step on the path of legalization, standardization and internationalization, government should actively support and promote the applications of UAV industry standards with our own intellectual property rights at home and abroad to seize the initiative and strong power of discourse in international competition.

2) Improving the core competitiveness of UAV enterprises and optimizing the patent layout

Firstly, on the basis of UAV industry development plan, all innovation subjects ought to accelerate the pace of breakthrough about fundamental and vital technology as well as innovation achievements transformation and 
industrialization. More peripheral patents, especially high quality patents for inventions should be developed centering around core technologies to break the foreign technology monopoly. Secondly, in aim to promote the optimization and upgrading of patent structure, more support policies should be introduced to speed up the layout of high-quality and high-level patents for inventions in the early stages of development. Existing phenomena, such as stressing quantity over quality and stressing application over protection, need to be revised. Then, more consideration should be taken to the establishment of market-oriented mechanism and model of collaborative innovation, including diverse subjects such as enterprises, universities, research institutions and government departments. Every innovation subjects of UAV technology in China should grab the chance to strengthen the interaction each other, devote into international cooperation and competition, and lay importance to the technology introduction, assimilation and re-innovation of advanced foreign technology to realize the great-leapforward development [15]. Finally, it is important to expedite the development of patent early warning mechanism, which provides foreign UAV industry information, markets and trends for domestic enterprises regularly in case of unnecessary patent trap.

3) Constructing UAV industry demonstration bases and supporting the key enterprises related to UAV industry

At national level, different level of economic basis, technological capacity and resources endowment in each region of China lead to different policies of UAV industry. Every region needs to define role orientation and major developing direction themselves, avoiding blind development and repeated construction, and breaking through the shackles of "big but not strong" issues in the developing process of industry. At regional level, local government, as enterprises direct administrator, they are duty-bound to take on a heavy responsibility to perfect supportive and funding policies and form some UAV industry demonstration bases with pleasant environment for innovation, powerful technological radiation and technical guidance, and strong international competitive ability to cultivate industry growth pole. As enterprises, to compete with leading enterprises at global market stage and get a long-term subsistence development, patent strategy should be based on the core competence. What enterprises should do are integrating innovation resources, increasing innovation investment, seizing chances of industrial transformation brought by technology upgrading, improving innovation competence to master the core technology system of UAV with independent intellectual property rights.

4) Innovating training mechanism high-level talents and perfecting the UAV management system

As a cross-disciplinary and cross-industry emerging industry, China's UAV development lacks talents with professional and compound knowledge. With gradual opening of the market, talents shortage will be larger because of the fact that UAV industry service system has not yet formed. Firstly, to improve the skills and quality of employees, a strict professional admittance system needs to be determined for those people who are engaged in drone pilots. Secondly, it's urged to establish the effective training mechanism which combines theory learning with practice training. Presently, university-enterprise jointly education is the ultimate approach for enterprises to do human resource investment and to integrate resources of universities and enterprises to promote the talents training. Finally, regulating the use of UAV and real-name registration system of UAV owners are needed to reduce risks of safety and invasion of privacy.

\section{References}

[1] Michael, S.C., Kristen, A.G., Lyle, J.M., Samuel, K.B. and Benjamin, S.P. (2015) Emerging Trends in China’s Development of Unmanned Systems. http://www.rand.org/pubs/research_reports/RR990.html

[2] Zhang, D.Q., Zhang, Y.L. and Li, D.D. (2015) Prediction and Analysis of Global UAV Market. Tactical Missile Technology, No. 2, 1-6.

[3] Lu, Y.K., Zhang, S.J., Liu, X.Q. and Chen, W.J. (2015) The Analysis and Advice Research on Patents of Universities in Shanghai Based on Effective Innovation Patents. Journal of Modern Information, No. 3, 91-96.

[4] Yang, Z.K. and Sun, Y.T. (2009) Analysis of Patent Holding Model Based on Valid Patent in China. Science and Technology Management Research, No. 2, 254-257.

[5] Chen, J. and Zhang, Y.J. (2015) Research on 3D-Printing Technology in China Based on Patent Map. Forum on Science and Technology in China, No. 11, 34-40.

[6] Huang, Q., Zhou, X.Q. and Yang, Z.Y. (2009) Review on the Research of TRIZ Technological Evolution Theory and It's Application. Science of Science and Management of S\&T, No. 4, 58-65.

[7] Mann, D. (2001) An Introduction to TRIZ: The Theory of Inventive Problem Solving. Creativity and Innovation Man- 
agement, 10, 123-125. http://dx.doi.org/10.1111/1467-8691.00212

[8] Park, H., Ree, J.J. and Kim, K. (2013) Identification of Promising Patents for Technology Transfer Using TRIZ Evolution Trends. Expert System with Applications, 40, 736-743. http://dx.doi.org/10.1016/j.eswa.2012.08.008

[9] Boretos, G.P. (2007) The Future of the Mobile Phone Business. Technological Forecasting and Social Change, 74, 311-340. http://dx.doi.org/10.1016/j.techfore.2005.11.005

[10] Trappey, C.V., Wu, H.Y., Taghaboni-Dutta, F. and Trappey, A.J.C. (2011) Using Patent Data for Technology Forecasting: China RFID Patent Analysis. Advanced Engineering Informatics, 25, 53-64. http://dx.doi.org/10.1016/j.aei.2010.05.007

[11] Freeman, L.C. (1979) Centrality in Social Networks: Conceptual Clarification. Social Networks, 1, $215-239$. http://dx.doi.org/10.1016/0378-8733(78)90021-7

[12] Zhou, X.Y., Dai, Y. and Qiu, C.Y. (2015) Research on Progress of Internet of Things at Library Based on Patentometrics. Library Journal, 2, 79-84.

[13] Eck, N.J. and Waltman, L. (2010) Software Survey: VOSviewer, a Computer Program for Bibliometric Mapping. Scientometrics, 84, 523-538.

[14] Dong, N.Q. (2014) A Research on the Situation, Difficulties and Countermeasures of China's General Aviation Development. Journal of Beijing Institute of Technology (Social Science Edition), No. 1, 110-117.

[15] Yu, J. and Chen, K.H. (2012) Current Situation and Challenge of Technological Innovations in Chinese Strategic Emerging industries: A patent-Bibilometric Perspective. Studies in Science of Science, No. 5, 682-695.

\section{Submit or recommend next manuscript to SCIRP and we will provide best service for you:}

Accepting pre-submission inquiries through Email, Facebook, LinkedIn, Twitter, etc.

A wide selection of journals (inclusive of 9 subjects, more than 200 journals)

Providing 24-hour high-quality service

User-friendly online submission system

Fair and swift peer-review system

Efficient typesetting and proofreading procedure

Display of the result of downloads and visits, as well as the number of cited articles

Maximum dissemination of your research work

Submit your manuscript at: http://papersubmission.scirp.org/ 